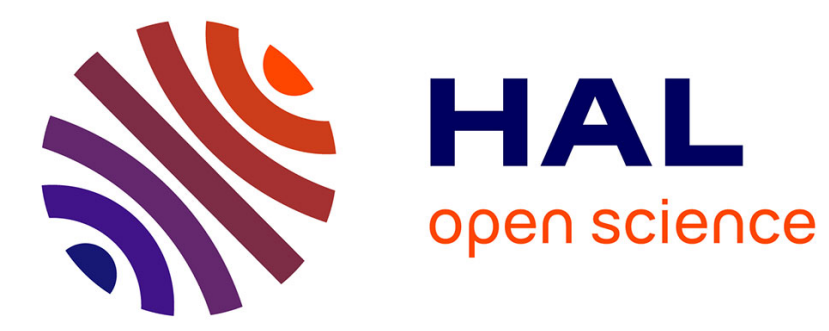

\title{
Theoretical analysis and characterization of the energy conversion and storage efficiency of photo-supercapacitors
}

\author{
Balthazar Pierre Lechene, Raphael Clerc, Ana Claudia Arias
}

\section{- To cite this version:}

Balthazar Pierre Lechene, Raphael Clerc, Ana Claudia Arias. Theoretical analysis and characterization of the energy conversion and storage efficiency of photo-supercapacitors. Solar Energy Materials and Solar Cells, 2017, 10.1016/j.solmat.2017.07.034 . hal-01583981

\section{HAL Id: hal-01583981 \\ https://hal.science/hal-01583981}

Submitted on 8 Sep 2017

HAL is a multi-disciplinary open access archive for the deposit and dissemination of scientific research documents, whether they are published or not. The documents may come from teaching and research institutions in France or abroad, or from public or private research centers.
L'archive ouverte pluridisciplinaire HAL, est destinée au dépôt et à la diffusion de documents scientifiques de niveau recherche, publiés ou non, émanant des établissements d'enseignement et de recherche français ou étrangers, des laboratoires publics ou privés. 


\title{
Theoretical analysis and characterization of the energy conversion and storage efficiency of photo-supercapacitors
}

\author{
Balthazar Pierre Lechene ${ }^{\mathrm{a}}$, Raphael Clerc ${ }^{\mathrm{b}}$, Ana Claudia Arias ${ }^{\mathrm{a}, *}$ \\ a Department of Electrical Engineering and Computer Sciences, University of California, Berkeley, CA 94720, USA \\ b Université de Lyon, UJM-Saint-Etienne, Institut d'Optique Graduate School, CNRS, UMR5516, Laboratoire Hubert Curien, F-42023, Saint-Etienne, France
}

\section{A R T I C L E I N F O}

\section{Keywords:}

Photo-supercapacitor

Solar cell

Supercapacitor

Photorechargeable system

Energy conversion and storage efficiency

\begin{abstract}
A B S T R A C T
The time-dependent dynamics of the charge and discharge of photo-supercapacitors (PSC), devices which combine a supercapacitor with a solar cell, are investigated using a semi-analytical model. For a given PSC, it is found that the maximum Energy Conversion and Storage Efficiency (ECSE) is a direct function of the Power Conversion Efficiency (PCE) and Fill Factor (FF) of the solar cell. The capacitance, series and shunt resistances of the supercapacitor affect the time constants of the PSC and the value of the maximum ECSE. To experimentally measure the maximum value of ECSE with at most 2 charge-discharge cycles, a simple experimental procedure is proposed, which consists in comparing the power flowing through the supercapacitor and the energy already stored in it. The theoretical results are validated with experiments on a PSC made from an organic solar cell and a commercial supercapacitor.
\end{abstract}

\section{Introduction}

Photo-supercapacitors (PSC) are devices combining solar cells with supercapacitors in order to simultaneously generate and store energy from light. They can be particularly useful as independent energy sources to power autonomous devices such as wearables and Internet of Things nodes [1-3], or to act as buffers to mitigate the effects of solar light fluctuations on energy generation $[4,5]$. One of the main advantages of PSC is their simplicity (only two elements), as they do not need interfacing electronics between the solar cell and the supercapacitor, thus offering a lot of flexibility in their design and fabrication [6]. PSC can be fabricated as a single stack where the generation and storage components share a common electrode, which considerably reduces resistive losses and minimizes footprint [7]. They can also be fabricated in specific formats, like a fiber [8], or using low-cost solution processing techniques compatible with flexible substrates $[1,2,9]$.

A typical figure of merit of PSC is the energy conversion and storage efficiency (ECSE) over a complete charge-discharge cycle, sometimes also called "overall efficiency" $[5,10]$ or "photoelectric conversion and storage efficiency" $[8,11]$. The ECSE of a PSC is measured by performing a charge-discharge experiment: during the charging phase, the solar cell is exposed to light, which charges the initially empty supercapacitor. After a certain amount of time, the charging is stopped and the supercapacitor is discharged, either at constant current [12] or into a given load [13]. The ECSE is then defined as the ratio of electrical energy discharged from the super-capacitor over the light energy received by the solar cell during the charging period.

The duration of the charging phase and the incident light power influence the measured ECSE value of a PSC: as the supercapacitor is charging, its voltage increases, which modifies the output power of the solar cell over time $[9,12]$. For a given light power, each system thus displays a maximum ECSE value. In order to identify this maximum, multiple charge-discharge experiments must be performed, each with a different charging time, which can be problematic if the solar cell's efficiency changes during the prolonged light exposure. While the maximum ECSE of a PSC cannot be higher than its solar cell's power conversion efficiency (PCE), the relation between the two can vary widely: in previous work $[10,11,14-16]$, the ratio ECSE/PCE can go as low as 0.12 [16] and as high as 0.81 [15].

In this work, we develop a theoretical model to investigate how the performance of a PSC relates to the characteristics of its solar cell and supercapacitor, and we demonstrate an experimental method to identify and reliably measure the maximum ECSE in a simple way. The model describes the temporal evolution of a PSC during charge and identifies how it is influenced by the solar cell's $\mathrm{J}-\mathrm{V}$ characteristic and by the supercapacitor's capacitance and parasitic resistances (shunt and series). It is found that the theoretical maximum ECSE depends only on the solar cell's PCE and its Fill Factor (FF), while the supercapacitor's shunt and series resistances can lower the effective ECSE under this theoretical value. The supercapacitor's capacitance mostly influences

\footnotetext{
* Corresponding author.

E-mail address: acarias@berkeley.edu (A.C. Arias).
} 
the time at which the maximum ECSE occurs. Moreover, the theoretical value of the solar cell's voltage upon occurrence of the maximum ECSE is determined to be solely a function of the FF and the $\mathrm{V}_{\text {oc }}$ of the solar cell. Based on the theoretical analysis, a method is proposed to experimentally determine the charging time yielding the maximum ECSE of a PSC, with at most two charge-discharge cycles. This method involves following in real time the power flowing to the supercapacitor and the corresponding stored energy and does not require prior knowledge of the capacitance of the supercapacitor. These results are validated by comparing charge-discharge experiments and simulations of an actual PSC made of an organic solar cell and a commercial supercapacitor.

\section{Experimental methods}

\subsection{Solar cell fabrication}

The solar cell fabrication was taken from ref. [9]. ITO-covered glass (from Thin Film Devices) were sequentially cleaned in acetone, isopropanol and water, then passed under UV-ozone plasma treatment for $30 \mathrm{~min}$. PEDOT:PSS (Heraeus Clevios VPAI 4083, $40 \mathrm{~nm}$ ) was spincoated and baked at $180{ }^{\circ} \mathrm{C}$ for $10 \mathrm{~min}$. After transfer in a glovebox, a PCDTBT:PC ${ }_{71} \mathrm{BM}$ (1:3.7 in ortho-dichlorobenzene with $5 \%$ dimethyl sulfoxide) solution was spin-coated above $(80 \mathrm{~nm})$. PCDTBT was purchased from Saint-Jean Photochimie and $\mathrm{PC}_{71} \mathrm{BM}$ from Solaris. Finally, PEIE (Sigma Aldrich) diluted to $0.048 \mathrm{wt} \%$ in ethanol was also spincoated and the whole device was annealed at $70{ }^{\circ} \mathrm{C}$ for $10 \mathrm{~min} .200 \mathrm{~nm}$ of aluminum were thermally evaporated to complete the devices.

\subsection{Electrical characterization}

The solar cells' J-V curves were acquired using a Keithley 2400. For PSC characterization, current and voltage measurements in part 4 were obtained using two synchronized Keithley 2400. For the sun spectrum, a solar simulator from Newport Oriel Sol1A (xenon lamp). The power was calibrated with a Newport System V reference silicon solar cell.

\section{Theory and calculations}

\subsection{Electrical circuit and equations}

For the purpose of this theoretical study, the solar cell - supercapacitor system is represented as a circuit comprising a solar cell, an ideal capacitor of capacitance $C$ (which can be assumed voltage dependent or not, as discussed later), a series resistance $R_{s}$, and a shunt resistance $R_{s h}$, as shown in Fig. $1 \mathrm{a} . \mathrm{V}_{\mathrm{pv}}$ is the voltage across the solar cell, $\mathrm{I}$ is the current generated by the solar cell, $\mathrm{V}_{\mathrm{Rs}}$ is the voltage across the series resistance and $\mathrm{V}_{\text {capa }}$ is the voltage across the supercapacitor and the shunt resistance. The current flowing through the supercapacitor is $i_{c}$. In this model, the solar cell's voltage $V_{p v}$, and current $I$ $\left(\mathrm{V}_{\mathrm{pv}}\right)$, are related together by the solar cell's I-V characteristic. The nonidealities of the solar cell are taken into account by its I-V characteristic through the variation of its apparent Fill Factor F. The shunt and series resistances of the circuit correspond in fact to the capacitor's internal equivalent series resistance (ESR) and shunt resistance.

Solar cells I-V characteristics are usually modeled by the Shockley diode equation. However, when accounting for internal resistances, the current becomes a self-consistent function of itself, making this expression difficult to deal with mathematically. Therefore, in this work, the solar cell's I-V characteristic is modeled with an empirical elliptic equation:

$I(V)=I_{s c} \frac{V_{0}}{V_{o c}} \frac{V-V_{o c}}{V-V_{0}}$

where $V_{o c}$ is the open circuit voltage of the solar cell and $I_{s c}$ its shortcircuit current. This equation fulfills the requirement $\mathrm{I}(0)=\mathrm{I}_{\mathrm{sc}}$ and $\mathrm{I}$
$\left(\mathrm{V}_{\mathrm{oc}}\right)=0 . \mathrm{V}_{\mathrm{o}}$ is a parameter (necessarily greater than $\mathrm{V}_{\mathrm{oc}}$ ) related to the Fill Factor and is representative of the solar cell's internal parasitic resistances. It can be shown that:

$V_{0}=V_{o c}\left[\frac{2 \sqrt{F^{3}}+F}{4 F-1}\right]=V_{o c} f(F)$

where $F$ is the Fill Factor and $f(F)$ represents the function in the brackets. A Fill Factor $\mathrm{F}=0.5$ leads to a ratio $\mathrm{V}_{0} / \mathrm{V}_{\text {oc }}$ equal to 1.2, whereas if $\mathrm{F}=0.8, \mathrm{~V}_{0} / \mathrm{V}_{\mathrm{oc}}=1.01$. (Note that in this model, the minimal value of $\mathrm{F}$ is limited to 0.25 , which is not really an issue as the Fill Factors of solar cells are typically higher). Fig. 1b shows I-V curves generated with this equation for $\mathrm{V}_{\mathrm{oc}}=0.9 \mathrm{~V}, \mathrm{I}_{\mathrm{sc}}=12 \mathrm{~mA}$ and $\mathrm{F}$ varying from $25 \%$ to $80 \%$. Compared to the Shockley diode equation, the main drawback of this expression of I-V is that the relative influence of the solar cell's series or shunt resistances on the Fill Factor is no longer explicit and thus cannot be specifically addressed. Still, this elliptic representation of I-V characteristics allows to realistically model a solar cell's overall electrical behavior, allowing to easily vary its Fill Factor, $\mathrm{V}_{\mathrm{oc}}$ and $\mathrm{I}_{\mathrm{sc}}$, while being integrable and differentiable.

The voltage and current parameters of the circuit of Fig. 1a follow the differential equation:

$C \frac{d V_{\text {capa }}}{d t}=I\left(V_{p v}\right)-\frac{V_{\text {capa }}}{R_{\text {sh }}}$

Which can be re-written as a function of $\mathrm{V}_{\mathrm{pv}}$ solely using $V_{\text {capa }}=V_{p v}-R_{S} I\left(V_{p v}\right)$ :

$C \frac{d V_{p v}}{d t}\left(1-R_{s} \frac{d I\left(V_{p v}\right)}{d V_{p v}}\right)=I\left(V_{p v}\right)-\frac{1}{R_{s h}}\left(V_{p v}-R_{s} I\left(V_{p v}\right)\right)$

If there are no series or shunt resistance (ideal supercapacitor), the equation reduces to the form below:

$C \frac{d V}{d t}=I(V)$

where $\mathrm{V}=\mathrm{V}_{\mathrm{pv}}=\mathrm{V}_{\text {capa. }}$. Both differential Eqs. (4) and (5) are non-linear and thus in principle difficult to solve. However, thanks to the elliptical expression of I(V) of Eq. (1), the simplified Eq. (5) can be analytically solved, as shown in Section 4.1. When series and shunt resistances are taken into account, a closed-form solution of the differential Eq. (4) can no longer be found. Eq. (4) is thus simply integrated numerically, avoiding time consuming numerical techniques usually employed to solve differential equations (such as Runge Kutta for instance) and their related potential stability issues. To do so, the differential Eq. (4) is rewritten as:

$C \frac{\left(1-R_{s} \frac{d I\left(V_{p v}\right)}{d V_{p v}}\right)}{I\left(V_{p v}\right)-\frac{1}{R_{s h}}\left(V_{p v}-R s I\left(V_{p v}\right)\right)} d V_{p v}=d t$

By calling $A\left(\mathrm{~V}_{\mathrm{pv}}\right)$ the left end side term, the circuit's time evolution can be determined by numerically integrating Eq. (7) for every value of voltage $\mathrm{V}_{\mathrm{pv}}$ ranging from $\mathrm{V}_{\mathrm{pv}}(\mathrm{t}=0)$ to $\mathrm{V}_{\mathrm{oc}}$ :

$\int_{V_{p v}(t=0)}^{V_{p v}} A(v) d v=\int_{0}^{t\left(V_{p v}\right)} d t=t\left(V_{p v}\right)$

The time $t\left(V_{p v}\right)$ is the time it takes for the system to reach a voltage across the solar cell equal to the value $\mathrm{V}_{\mathrm{pv}}$. From the value of $\mathrm{V}_{\mathrm{pv}}$ and the elliptical expression of $\mathrm{I}\left(\mathrm{V}_{\mathrm{pv}}\right)$, it is possible to deduce the value of all the circuit's parameters: $V_{\text {capa }}$, $i_{c}$, the quantity of charges and energy stored in the supercapacitor. The system's charge is always considered to start from a completely empty supercapacitor $\left(\mathrm{V}_{\text {capa }}(\mathrm{t}=0)=0\right)$. Therefore, the starting voltage for the integral calculation is determined by the initial condition: $V_{p v}(t=0)=R s I\left(V_{p v}(t=0)\right)$. 


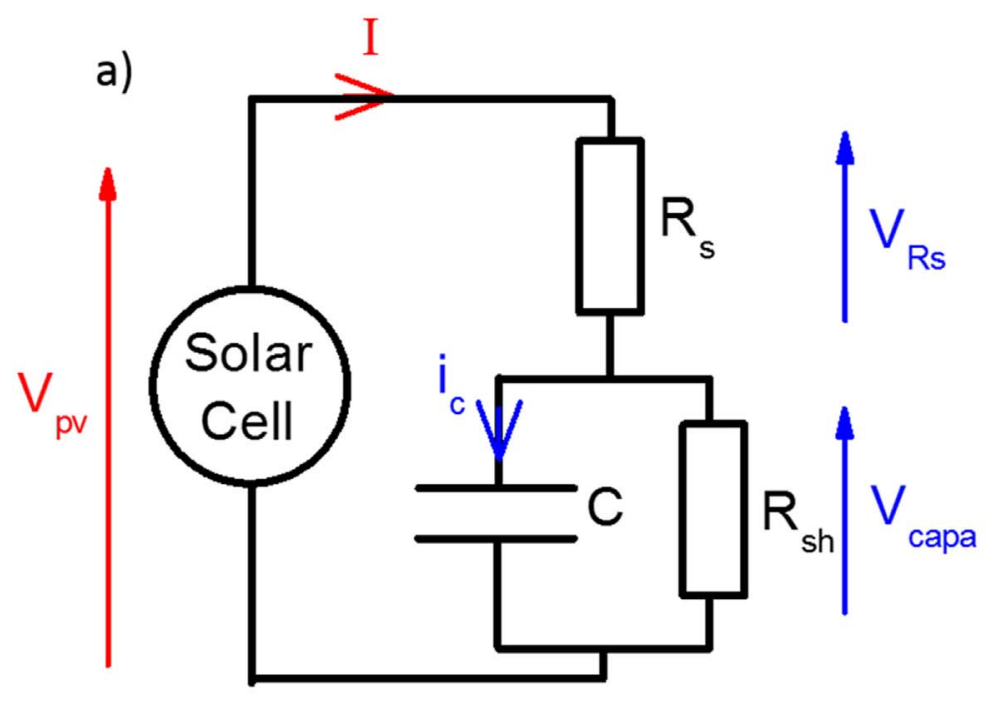

b)

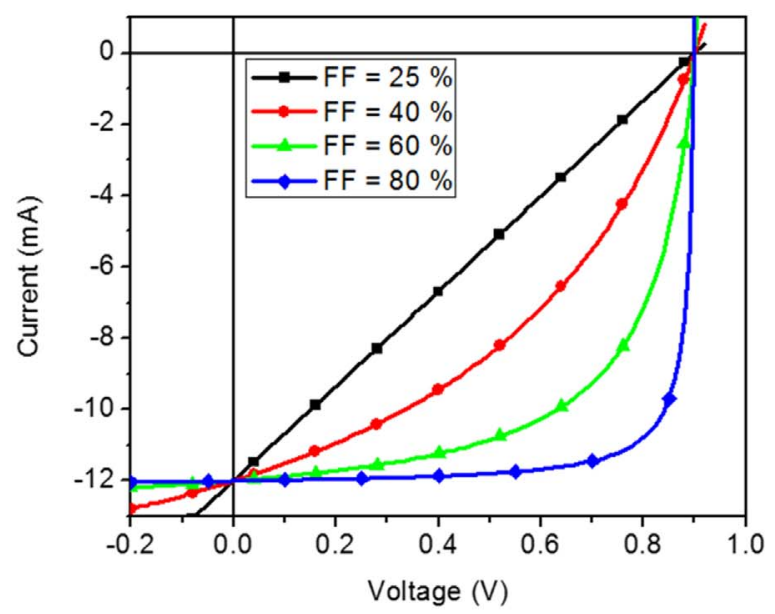

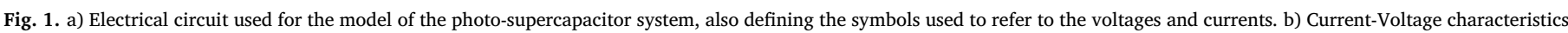
obtained using the elliptic Eq. (1), with Fill Factors varying between $25 \%$ and $80 \%$.

\subsection{Definition and modeling of the energy conversion and storage efficiency (ECSE)}

During the charging period, the ECSE as a function of the time of charge $t$ is defined as $\operatorname{ECSE}(t)=\frac{E_{\text {stored }}(t)}{E_{\text {light }}(t)}$ where $\mathrm{E}_{\text {stored }}$ is the energy stored in the capacitor at the time $t$ and $\mathrm{E}_{\text {light }}$ the light energy received by the solar cell since the start of the charge. Under constant uniform illumination, which will always be the case in the following study, $E_{\text {light }}(t)=P_{\text {light }} \times t$, where $\mathrm{P}_{\text {light }}$ is the light power received by the cell (for numerical calculations, $\mathrm{P}_{\text {light }}$ will be taken equal to $100 \mathrm{~mW} / \mathrm{cm}^{2}$, the standard 1-sun condition). By definition,

$E_{\text {stored }}(t)=\int_{0}^{t} V_{\text {capa }}(\tau) \cdot i_{c}(\tau) d \tau$

It has to be noted that the commonly used Eq. (9):

$E_{\text {stored }}(t)=\frac{1}{2} C V_{\text {capa }}(t)^{2}$

is solution of Eq. (8) only in the particular case where the capacitance C is time, voltage or charge independent, which may not always be the case for supercapacitors. Eq. (8) does not technically require to know the value of the capacitance $C$ to determine the energy stored, provided that $\mathrm{V}_{\text {capa }}(\mathrm{t})$ and $\mathrm{i}_{\mathrm{c}}(\mathrm{t})$ are known. From those equations, ECSE can be written as:

$\operatorname{ECSE}(t)=\frac{\int_{0}^{t} V_{\text {capa }}(\tau) \cdot i_{c}(\tau) d \tau}{P_{\text {light }} t}$

If the capacitance is constant with voltage, then Eq. (9) can be injected into Eq. (10).

Ideally, all the energy stored during the charging phase should be extracted during the discharging phase. However, storage may be penalized by parasitic losses (leakage current, relaxation of species,...) which can be taken into account with an energy storage efficiency factor defined as $\eta_{\text {storage }}=\frac{E_{\text {discharged }}}{E_{\text {charged }}}$ where $E_{\text {charged }}$ and $E_{\text {discharged }}$ are respectively the total energy charged into and discharged from the supercapacitor during the complete. Therefore, it is assumed that all the conclusions from the analysis of the charging regime can be directly translated to the discharging regime by use of this storage efficiency factor. In particular:

$E C S E_{\text {discharge }}=E C S E_{\text {charge }} \times \eta_{\text {storage }}$

This definition of the storage efficiency differs from the one sometimes found in the literature [6,8,10,17] where $\eta_{\text {storage-literature }}=\frac{E C S E}{P C E}$. Unless noted otherwise, all of the following study refers to the charging regime and so ECSE corresponds to $\mathrm{ECSE}_{\text {charge. }}$

\section{Results and discussion}

In the following, the temporal evolution of the solar-cell - supercapacitor system in the charging regime is investigated step by step, considering first the simplified system with ideal solar cell and supercapacitor, then non-ideal solar cell with ideal supercapacitor, and finally both non-ideal components.

\subsection{Circuit with no parasitic resistance in the capacitor}

In this first section, series resistance $R_{s}$ and shunt resistance $R_{s h}$ are neglected to analyze the ideal scenario.

\subsubsection{Ideal solar cell}

If the solar cell is assumed ideal then, $I(V)=I_{s c}$ for $\mathrm{V}<\mathrm{V}_{\text {oc }}$, while for $\mathrm{V}=\mathrm{V}_{\mathrm{oc}}$, the current instantaneously drops to zero. In this case, the system evolves linearly:

$V(t)=\frac{I_{s c}}{C} t$

The differential Eq. (5) remains valid until $\mathrm{V}$ reaches $\mathrm{V}_{\mathrm{oc}}$, then the charging stops, which is achieved at the "time of full charge" $t_{c}$ given by:

$t_{c}=\frac{C V_{o c}}{I_{s c}}$

Assuming a voltage independent capacitance C, Eq. (9) is valid and the ECSE is simply given by:

$\operatorname{ECSE}(t)=\frac{I_{s c}^{2}}{2 C P_{\text {light }}} t\left(t \leq t_{c}\right)$

$\operatorname{ECSE}(t)=\frac{C V_{o c}^{2}}{2 P_{\text {light }} t}\left(t \geq t_{c}\right)$

For times $t$ longer than $t_{c}$, the charging of the capacitance is completed, no more energy can be stored, and, as the device is still continuously illuminated, the ECSE decreases as a function of $1 / \mathrm{t}$. The ECSE thus reaches a maximum for a time $t_{E \max }$ equal here to $t_{c}$, and $\mathrm{ECSE}_{\text {max }}$ is given by: 
$E C S E_{\max }=\frac{I_{s c} V_{o c}}{2 P_{\text {light }}}=\frac{1}{2} P C E\left(t=t_{c}\right)$

In this ideal case, the maximum value of ECSE (ECSE $E_{\max }$ ) is equal to exactly half of the solar cell maximum efficiency under the illumination power $\mathrm{P}_{\text {light }}$, directly linking the ECSE to the solar cell's PCE. This value is independent of the capacitance $\mathrm{C}$, which only impact the charging time $t_{c}$. This initial study confirms that the variation of ECSE with time is inherent to the system and that this temporality can be tuned with the parameters of the capacitor and the solar cell. However, because they deal only with ideal components, these results fail to indicate the role played by the FF of the solar cell.

\subsubsection{Non-ideal solar cell (with ideal capacitance)}

To take into account the solar cell non ideality and in particular to investigate the impact of the FF, the elliptical expression of the I-V curve (Eq. (1)) is used in combination with Eq. (5) and the resulting differential equation is solved. The result describes the time evolution of the voltage $\mathrm{V}$ :

$t(V)=\frac{C V_{o c}}{I_{s c} V_{0}}\left(V-\left(V_{0}-V_{o c}\right) \ln \left[1-\frac{V}{V_{o c}}\right]\right)$

The charging dynamics at the beginning of the charge ( $\mathrm{V}$ close to 0 ) is similar to the previous case with the ideal solar cell, as Eq. (17) can be approximated to be equal to Eq. (13).

$t(V \rightarrow 0) \approx \frac{C V_{o c}}{I_{s c} V_{0}}\left(V+V\left(\frac{V_{0}-V_{o c}}{V_{o c}}\right)\right)=\frac{C V}{I_{s c}}$

However, when $\mathrm{V}$ tends to $\mathrm{V}_{\mathrm{oc}}$, $\mathrm{t}$ tends to infinity and full charge is never actually achieved. In practice, an effective full-charge time $t_{c}$ can still be defined using the criteria $\mathrm{V}=\alpha \mathrm{V}_{\mathrm{oc}}$, with $\alpha=0.95$ for instance. Under this approximation, as $\ln (0.05) \sim-3$, Eq. (17) combined with Eq. (2) gives $t_{c}$ :

$t_{c} \sim \frac{C V_{o c}}{I_{s c}}\left[3-\frac{8 F-2}{2 \sqrt{F^{3}}+F}\right]$

In other words, the value of $\mathrm{V}=0.95 \mathrm{~V}_{\mathrm{oc}}$ is reached in a time equal to $\frac{C V_{o c}}{I_{s c}}$ if the Fill Factor $F$ is close to 1 (as in the ideal case), and can be as much as three times longer if the Fill Factor is poor $(F=0.25)$. In this later case, the time $t_{\mathrm{Emax}}$ at which ECSE reaches its maximum is no longer equal to the time of full charge. Using Eqs. (9) and (10), the maximum of ECSE is achieved when:

$\frac{d E C S E}{d t}\left(t=t_{\text {Emax }}\right)=\frac{C V}{2 P t}\left(2 \frac{d V}{d t}-\frac{V}{t}\right)=0$

Using Eq. (5), this condition can be re-written as:

$C V \frac{d V}{d t}=V i_{c}=\frac{1}{2} \frac{C V^{2}}{t}=\frac{1}{t} \int_{0}^{t} V i_{c} d t$

Unfortunately, it is not possible to obtain a closed form solution of Eq. (21). However, an approximated value of $t_{E \max }$ can be found by calculating $\mathrm{V}_{\mathrm{Emax}}$, the voltage across the supercapacitor at time $t_{\mathrm{Emax}}$. Eq. (21) can be written as:

$i_{c}\left(V_{E \max }\right)=\frac{1}{2} \frac{C V_{E \max }}{t\left(V_{E \max }\right)}$

Introducing $\delta \mathrm{V}$ such as $V_{E \max }=V_{o c}-\delta \mathrm{V}$, it can be shown that:

$\delta V \approx V_{o c} \exp [-a F+b]$

Where $a=5.3$ and $b=0.07$ (see Appendix A for details). Therefore, Eq. (23) provides an approximate value of $\mathrm{V}_{\mathrm{Emax}}$ as a function of the Fill Factor F:

$V_{\text {Emax }}=V_{o c}\left(1-e^{-a F+b}\right)$

It is noteworthy that $\mathrm{V}_{\mathrm{Emax}}$ depends only on the Fill Factor $\mathrm{F}$ and on
$\mathrm{V}_{\text {oc }}$ and not on the capacitance. $\mathrm{V}_{\mathrm{Emax}}$ can then be compared to the solar cell's maximum power point voltage $\mathrm{V}_{\text {ppmax }}$. According to Eq. (1), $\mathrm{V}_{\mathrm{ppmax}}$ is given by:

$V_{\text {ppmax }}=V_{o c}\left(f(F)-\sqrt{f(F)^{2}-f(F)}\right)$

A detailed comparison between $\mathrm{V}_{\mathrm{Emax}}$ and $\mathrm{V}_{\text {ppmax }}$ (see Fig. $\mathrm{S} 1$ in Supplementary material) shows that $\mathrm{V}_{\mathrm{Emax}}$ is always higher than $\mathrm{V}_{\mathrm{ppmax}}$, and the difference between the two is maximum when $\mathrm{F}=0.36$ and then decreases as the Fill Factor gets closer to 1 (where they become equal). This result indicates that the maximum ECSE of the PSC is reached after the solar cell has passed its maximum power conversion efficiency. From the expression of $V_{E \max }$ it is possible to deduce $t_{\mathrm{Emax}}$ and ECSE $_{\max }$ (cf Appendix A for calculations and for the definition of $g$ (F)) using respectively Eqs. (17) and (9).

$t_{E \max }=\frac{C V_{o c}}{I_{s c}} \frac{\left(1-e^{g(F)}\right)+(1-f(F)) g(F)}{f(F)}=\frac{C V_{o c}}{I_{s c}} h(F)$

Like the time of maximum charge $t_{c}, t_{E \max }$ is proportional to the ratio $\frac{C V_{o c}}{I_{s c}}$ and depends on a function of the Fill Factor named $h(F)$, which ranges between 1.0 and 1.3 (depending on the value of F). The value of $\mathrm{ECSE}_{\max }$ is then given as:

$E C S E_{\max }=\frac{V_{o c} I_{s c}}{P_{\text {light }}} \frac{\left(1-e^{g(F)}\right)^{2}}{2 h(F)}=\operatorname{PCEk}(F)$

where $P C E=\frac{V_{o c} I_{s c} F}{P_{\text {light }}}$, and $k(F)$ is the function regrouping all the terms depending solely on the Fill Factor F. A plot of the evolution of $k(F)$ and $h(F)$ as a function of $\mathrm{F}$ and their exact expressions are given in Supplemental Information. The evolution of the ratio of $\mathrm{ECSE}_{\max } / \mathrm{PCE}$ (effectively the function $k(F)$ ) and of $\operatorname{ECSE}_{\max }$ (calculated for a $\mathrm{V}_{\mathrm{oc}}=$ $1 \mathrm{~V}$ and $I_{s c}=10 \mathrm{~mA}$ ) as a function of $\mathrm{F}$ are plotted in Fig. 2. Mathematically, ECSE $E_{\max }$ does not depend on the capacitance, but solely on the solar cell's characteristics (and on the light power): $V_{\text {oc }}, I_{s c}$ and the Fill Factor. While ECSE $_{\max }$ increases with the Fill Factor, it flattens out for $\mathrm{F}$ superior to 0.8 . The ratio $\mathrm{ECSE}_{\max } / \mathrm{PCE}$ decreases from $0.81(\mathrm{~F}=$ $0.25)$ to $0.5(F=1)$, the same result as found previously for the ideal solar cell.

Therefore, the model presented above allows to estimate the theoretical maximum ECSE of a photo-supercapacitor system once the solar cell's I-V characteristics is known (assuming an ideal supercapacitor with constant capacitance). This value is proportional to the solar cell's PCE and more precisely, directly proportional to its $\mathrm{V}_{\mathrm{oc}}$ and $\mathrm{I}_{\mathrm{sc}}$. The ratio between ECSE $_{\max }$ and PCE depends on the Fill Factor F and is below unity overall. The capacitor only influences the time to the maximum of ECSE $t_{E \max }$ through its capacitance (though the role of the parasitic resistances have not appeared yet). These results lead to the

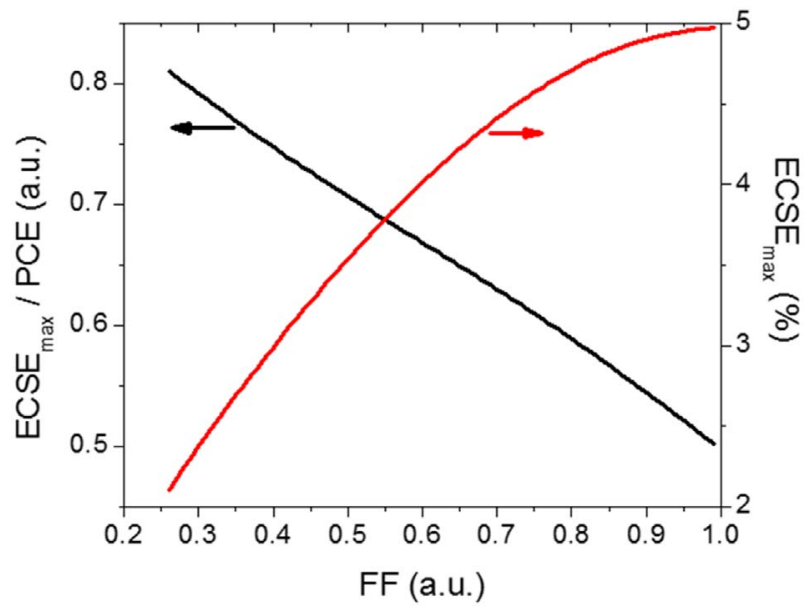

Fig. 2. Ratio of $\mathrm{ECSE}_{\max } / \mathrm{PCE}$ as a function of the solar cell's FF and an example of ECSE $_{\max }$ calculated with Eq. (27) and $\mathrm{V}_{\mathrm{oc}}=1 \mathrm{~V}$ and $\mathrm{I}_{\mathrm{sc}}=10 \mathrm{~mA}$. 

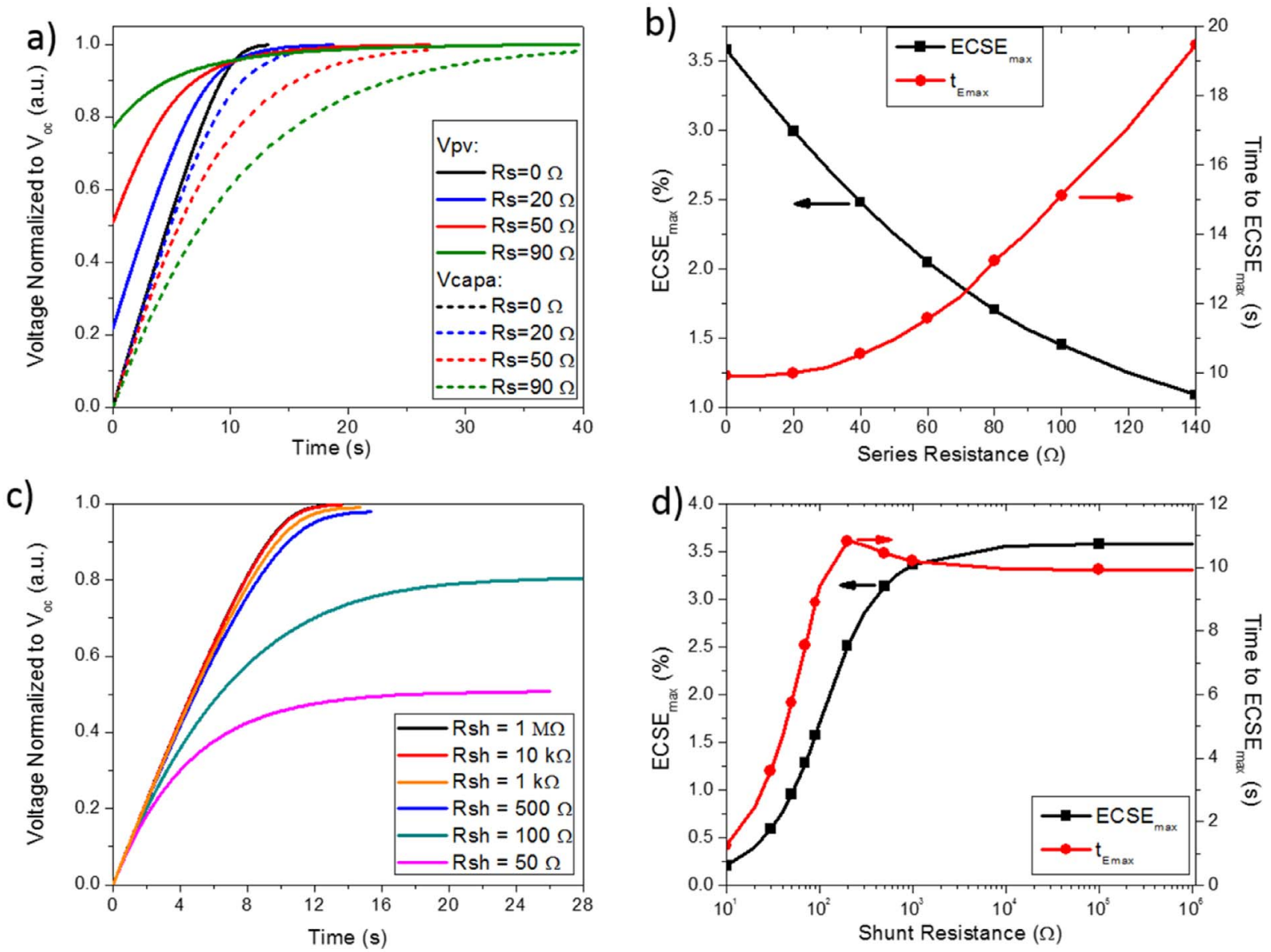

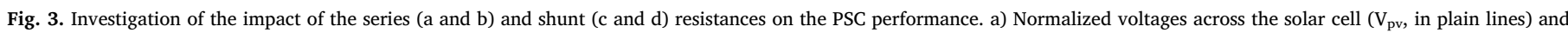

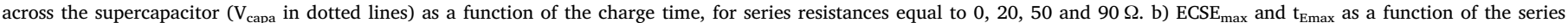

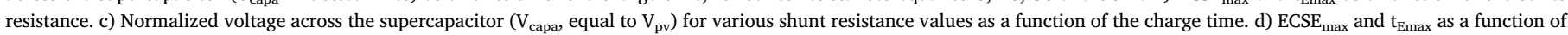
the shunt resistance.

first order conclusion that an efficient solar cell is the necessary foundation for an efficient photo-supercapacitor system, as expected intuitively.

\subsection{Non-ideal solar cell and supercapacitor}

The series or shunt resistances of the supercapacitor can generate energy losses that affect the energy transfer between the solar cell and the supercapacitor. To investigate their impact, a series of simulations is performed using the model described in Section 3.1 and numerically calculating Eq. (7). For those simulations, the solar cell's I-V curve is modeled by the elliptical formula with values typical of an organic solar cell [9] $\mathrm{V}_{\mathrm{oc}}=0.9 \mathrm{~V}, \mathrm{I}_{\mathrm{sc}}=10 \mathrm{~mA}$ and $\mathrm{F}=0.6(\mathrm{PCE}=5.4 \%)$, with a capacitance of $0.1 \mathrm{~F}$. Once the voltage across the solar cell reaches a certain value fixed at $1 \mathrm{mV}$ below the $\mathrm{V}_{\text {oc }}$ (using the exact $\mathrm{V}_{\text {oc }}$ makes the integral divergent), the system is deemed to have reached steady-state and the simulation stops. First, only series resistance are varied from 0 to $140 \Omega$, with the shunt resistance fixed at a very high value $(\geq 1 \mathrm{~T} \Omega)$. Fig. 3a shows the evolution of the voltage across the solar cells $V_{p v}$ (plain lines) and the capacitor $\mathrm{V}_{\text {capa }}$ (dotted lines) normalized to $\mathrm{V}_{\text {oc }}$ as a function of time for $\mathrm{R}_{\mathrm{s}}$ values of $0 \Omega, 20 \Omega, 50 \Omega$ and $90 \Omega$. When $\mathrm{R}_{\mathrm{s}}=$ $0, \mathrm{~V}_{\mathrm{pv}}$ and $\mathrm{V}_{\text {capa }}$ are equal and have the same behavior, starting from $0 \mathrm{~V}$ at $\mathrm{t}=0 \mathrm{~s}$ and then saturating at $\mathrm{V}_{\mathrm{oc}}$. When $\mathrm{Rs} \neq 0, \mathrm{~V}_{\text {capa }}$ still starts from $0 \mathrm{~V}$ but $\mathrm{V}_{\mathrm{pv}}$ starts at a higher voltage, determined by $V_{p v}(0)=R_{s} I\left(V_{p v}(0)\right)$. The starting current produced by the solar cell is thus lower than in the case with no $R_{s}$. Therefore, the capacitor needs a longer time to charge, as seen in the dynamic of $\mathrm{V}_{\text {capa }}$ in Fig. 3.
However, in the final state, the current is null, so $V_{p v}=V_{\text {capa }}=V_{o c}$ for any value of $R_{s}$. Thus, the series resistance modifies the dynamics of the charging regime, but not the final steady-state of the system. The values of $\mathrm{ECSE}_{\max }$ and $\mathrm{t}_{\mathrm{Emax}}$ are directly impacted by the series resistance, as shown on Fig. 3b. While ECSE $E_{\max }$ starts declining as soon as the series resistance is above zero, $t_{\mathrm{Emax}}$ is not significantly affected before $R_{s}=$ $40 \Omega$. Between $R_{s}$ values of $0 \Omega$ and $140 \Omega, t_{\mathrm{Emax}}$ doubles and $\mathrm{ECSE}_{\max }$ is divided by 3.5 . Therefore, high series resistances are very detrimental to the $\mathrm{ECSE}_{\max }$ and to $\mathrm{t}_{\mathrm{Emax}}$. For series resistance to be negligible, they should not result in a significant difference between $\mathrm{V}_{\mathrm{pv}}$ and $\mathrm{V}_{\text {capa }}$ in particular at $\mathrm{t}=0$. This suggests that the maximum tolerable series resistance value should verify: $R_{s} \ll V_{o c} / I_{s c}$.

In order to assess the effect of shunt resistance on the system (with no series resistance), simulations are performed with $R_{s h}$ ranging from $1 \mathrm{M} \Omega$ to $50 \Omega$. The evolution of the voltage across the capacitor and solar cell $\left(\mathrm{V}_{\text {capa }}=\mathrm{V}_{\mathrm{pv}}\right)$ as a function of time is plotted in Fig. 3c. For $\mathrm{R}_{\mathrm{sh}}$ from $1 \mathrm{M} \Omega$ to $10 \mathrm{k} \Omega$, the circuit behaves in an identical way that corresponds to the ideal case with infinite shunt resistance. A discrepancy starts appearing only for $R_{s h} \leq 1 \mathrm{k} \Omega$. This discrepancy is small until $R_{s h}$ $=500 \Omega$ but gets very noticeable below. For all values of $R_{\text {sh }}$, the dynamics around $t=0 \mathrm{~s}$ are identical. Each curve breaks away from the ideal scenario earlier as $R_{\text {sh }}$ decreases. Contrary to the series resistance case, the final steady-state is strongly affected by the shunt resistance. The current going through the shunt resistance depends on $V_{\text {capa }}$ and follows Ohm's law. For any value of $\mathrm{R}_{\mathrm{sh}}$, because at $\mathrm{t} \sim 0 \mathrm{~s}, \mathrm{~V}_{\text {capa }} \sim 0 \mathrm{~V}$ the current initially going through the shunt resistance is negligible. Then, as the supercapacitor charges, more and more current passes 
through the shunt resistance, penalizing the current going to the supercapacitor and slowing down the charge. In steady-state, the voltage never reaches $\mathrm{V}_{\mathrm{oc}}$. Instead, the final voltage is such that $V_{p v}(t \sim \infty)=R_{s h} I\left(V_{p v}(t \sim \infty)\right)$, where all the current generated by the solar cell goes through the shunt resistance. Again, It is possible to derive the maximal tolerable value of $R_{\text {sh. }}$. The impact of the shunt resistance remains negligible as long as that the final voltage remains close to $\mathrm{V}_{\text {oc }}$ and thus $R_{\text {sh }} I(\infty) \sim V_{\text {oc }}$. This can be effectively translated as $R_{s h} \frac{I_{s c}}{10} \geq V_{o c}$. In the current simulation, this condition is verified for $\mathrm{R}_{\mathrm{sh}}$ $\geq 900 \Omega$. The influence of the shunt resistance on ECSE $_{\max }$ and $t_{\mathrm{Emax}}$ is summarized by Fig. $3 \mathrm{~d}$. As long as $\mathrm{R}_{\mathrm{sh}}$ verifies the negligibility criterion, $E C_{\text {max }}$ and $t_{E \max }$ remain constant with decreasing $R_{\text {sh }}$. However, as soon as the shunt resistance is below $1 \mathrm{k} \Omega, \mathrm{ECSE}_{\max }$ decreases sharply, going from $3.5 \%$ to $1.5 \%$ within one order of magnitude of resistance. $\mathrm{t}_{\mathrm{Emax}}$ starts by sligthly increasing from $10.0 \mathrm{~s}$ to $10.7 \mathrm{~s}$ (for $300 \Omega$ ) then sharply decreases to $3.5 \mathrm{~s}$ within one order of magnitude as well. These observations are consistent with the influence of the shunt resistance highlighted above: when $\mathrm{R}_{\text {sh }}$ is below the threshold identified earlier, a significant portion of power is diverted away from the supercapacitor during the charge, which reduces ECSE $_{\text {max }}$. At any time during the charge, the amount of power lost into the resistance rather than going in the supercapacitor increases is equal to $\frac{V_{\text {capa }}^{2}}{R_{\text {sh }}}$. Therefore, the lower the shunt resistance, the earlier during the charge these losses become significant and the earlier is the occurrence of $t_{\mathrm{Emax}}$.

To evaluate how the shunt and series resistance losses can degrade the system ECSE, simulations are run for different FF, series and shunt resistances. The dependence of $\mathrm{ECSE}_{\max }$ normalized to PCE and to $\mathrm{V}_{\mathrm{oc}}{ }^{*} \mathrm{I}_{\mathrm{sc}}$ as a function of the solar cell's FF are plotted in Figs. $4 \mathrm{a}$ and $\mathrm{b}$ for 4 different resistance scenarios (infinite shunt resistance and $\mathrm{R}_{\mathrm{s}}=10 \Omega$ or $40 \Omega$; or no series resistance and $\mathrm{R}_{\text {sh }}=1000 \Omega$ or $300 \Omega$ ). The curve of the ideal case (no shunt or series resistance) is also given as a reference. The curves with parasitic resistances mimic the overall trend of the ideal scenario, but are shifted to lower $\mathrm{ECSE}_{\max }$ values. In the cases with significant series resistance, the ratio $\mathrm{ECSE}_{\max } /\left(\mathrm{V}_{\mathrm{oc}}{ }^{*} \mathrm{I}_{\mathrm{sc}}\right)$ generally increases with $\mathrm{FF}$ but there is an onset of decrease after a peak for very high FF values $(\mathrm{F}>0.9)$. On the curve of $\mathrm{ECSE}_{\max } / \mathrm{PCE}$, this phenomenon appears as a sharper declining slope. This effect is due to the fact that, at such high FF, $\mathrm{V}_{\mathrm{Emax}}, \mathrm{V}_{\mathrm{ppmax}}$ and $\mathrm{V}_{\mathrm{oc}}$ are almost identical, and the current stays almost equal to $\mathrm{I}_{\mathrm{sc}}$ up to these voltages. As a result, the ratio of energy losses to energy generated is very high around $V_{\mathrm{Emax}}$ and can be written as $\frac{R_{S} I_{s c}^{2}}{V_{E \max } I_{s c}}=\frac{R_{S} I_{s c}}{V_{E \operatorname{Emax}}}$. These losses are much higher than in the cases with lower FF, and as a result ECSE ${ }_{\max }$ is lower for a higher FF.
Overall, as expected, both series and shunt resistance of the circuit can have a strong impact on the $\mathrm{ECSE}_{\max }$ of the photo-supercapacitor system, and therefore reduce it compared to the ideal value expected from Eq. (27). Thus, if the series resistance is not negligible, it can be detrimental for the solar cell to have too high of a FF. It is important to note that, while the values of $\mathrm{ECSE}_{\max } / \mathrm{PCE}$ (or of $\mathrm{ECSE}_{\max } /\left(\mathrm{V}_{\text {oc }}{ }^{*} \mathrm{I}_{\mathrm{sc}}\right.$ )) as a function of FF calculated with $R_{s}=0$ and $R_{s h}=\infty$ correspond to the ideal scenario for any system, the exact values of this ratio for the values of resistances shown here are specific to the simulation parameters. For example, a system with a solar cell with $\mathrm{FF}=0.5, \mathrm{~V}_{\mathrm{oc}}=0.9 \mathrm{~V}$ and $\mathrm{I}_{\mathrm{sc}}=12 \mathrm{~mA}(\mathrm{PCE}=5.4 \%)$ and a series resistance of $40 \Omega$ should expect a ratio $\mathrm{ECSE}_{\max } / \mathrm{PCE}$ equal to 0.455 . However, a system with the same series resistance and a cell with the same $\mathrm{FF}=0.5$, but with $\mathrm{V}_{\text {oc }}=$ $0.6 \mathrm{~V}$ and $\mathrm{I}_{\mathrm{sc}}=18 \mathrm{~mA}(\mathrm{PCE}=5.4 \%)$ should expect a ratio $\mathrm{ECSE}_{\max } /$ PCE equal to 0.28 only. If instead the series resistance was negligible in both systems, then they would both have an $\mathrm{ECSE}_{\max } / \mathrm{PCE}$ ratio of 0.71 and $\mathrm{ECSE}_{\max }=3.83 \%$. When significant, the exact influence of the resistances on the system depends on how they compare to $\mathrm{I}_{\mathrm{sc}}$ and $\mathrm{V}_{\mathrm{oc}}$.

The evolution of $\mathrm{ECSE}_{\max } / \mathrm{V}_{\text {oc }}{ }^{*} \mathrm{I}_{\mathrm{sc}}$ or $\mathrm{ECSE}_{\max } / \mathrm{PCE}$ as a function of FF can also be used to gauge the "degree of ideality" of a given photosupercapacitor system. Fig. 4 shows these ratios for PSC systems extracted from the existing literature [5,8-17]. The four previous works who characterized ECSE as a function of time and therefore report $\mathrm{ECSE}_{\text {max }}$ are marked in red. For the others, the reported ECSE values suffer both from the resistances and from probably being away from ECSE $_{\max }$. Nonetheless most of the points are well below the ideal EC$\mathrm{SE}_{\max }$ value for the solar cell they report, meaning that those systems are significantly impacted by their resistive losses. As a matter of fact, those works often report an equivalent series resistance (ESR) value for their supercapacitor in tens or even hundreds of Ohm. The only data point situated on the ideal curve corresponds to the work of Zhang et al. [15], whose PSC system has a wire architecture, where a titanium fiber ensures the electrical connection between the fiber-shaped solar cell and supercapacitor. It could be that this specific form factor limits the impact of resistances. It is also possible that this particular system benefits from effects unaccounted for in the simulations (such as a nonconstant capacitance). Overall, these results highlight the importance of mitigating the influence of the resistances of the system. In particular, Wee et al. [7] reported that building a photo-supercapacitor as a single stack can result in a $43 \%$ drop of the system's series resistance compared to connecting the solar cell and the supercapacitor externally (however, they do not report the ECSE in either cases). Independently of the solar cell used, improving the supercapacitor and the circuit a)

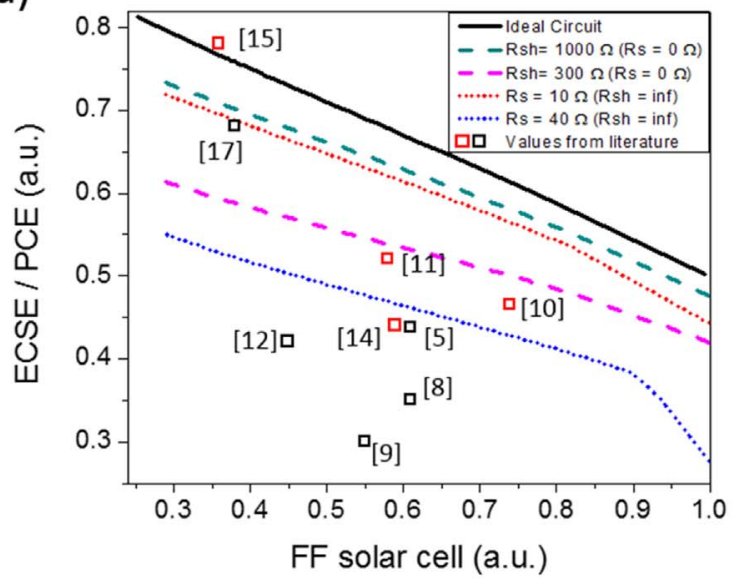

b)

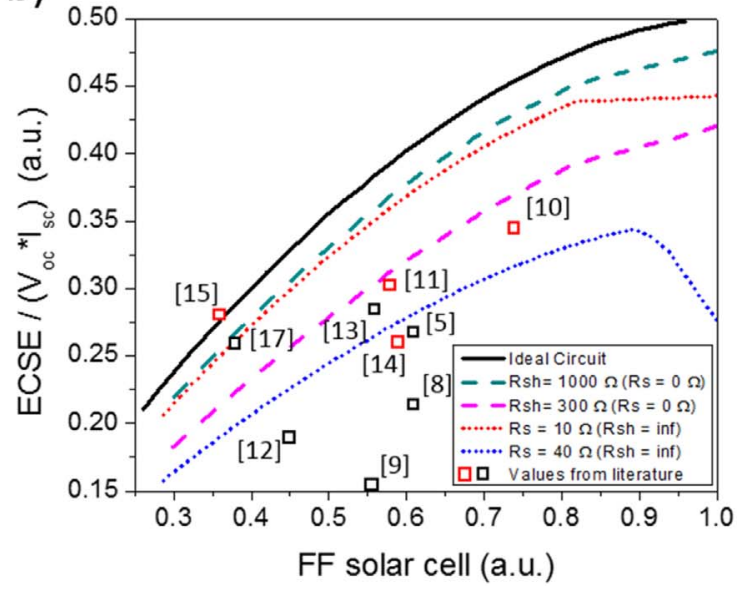

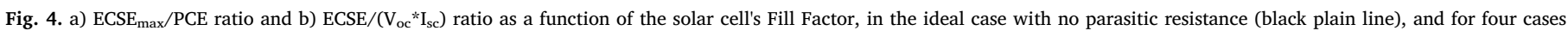

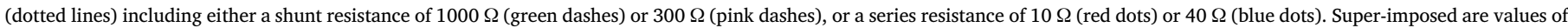

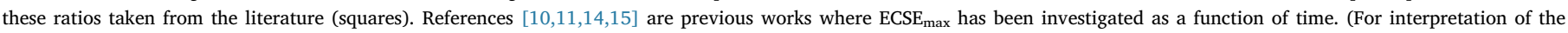
references to color in this figure legend, the reader is referred to the web version of this article) 

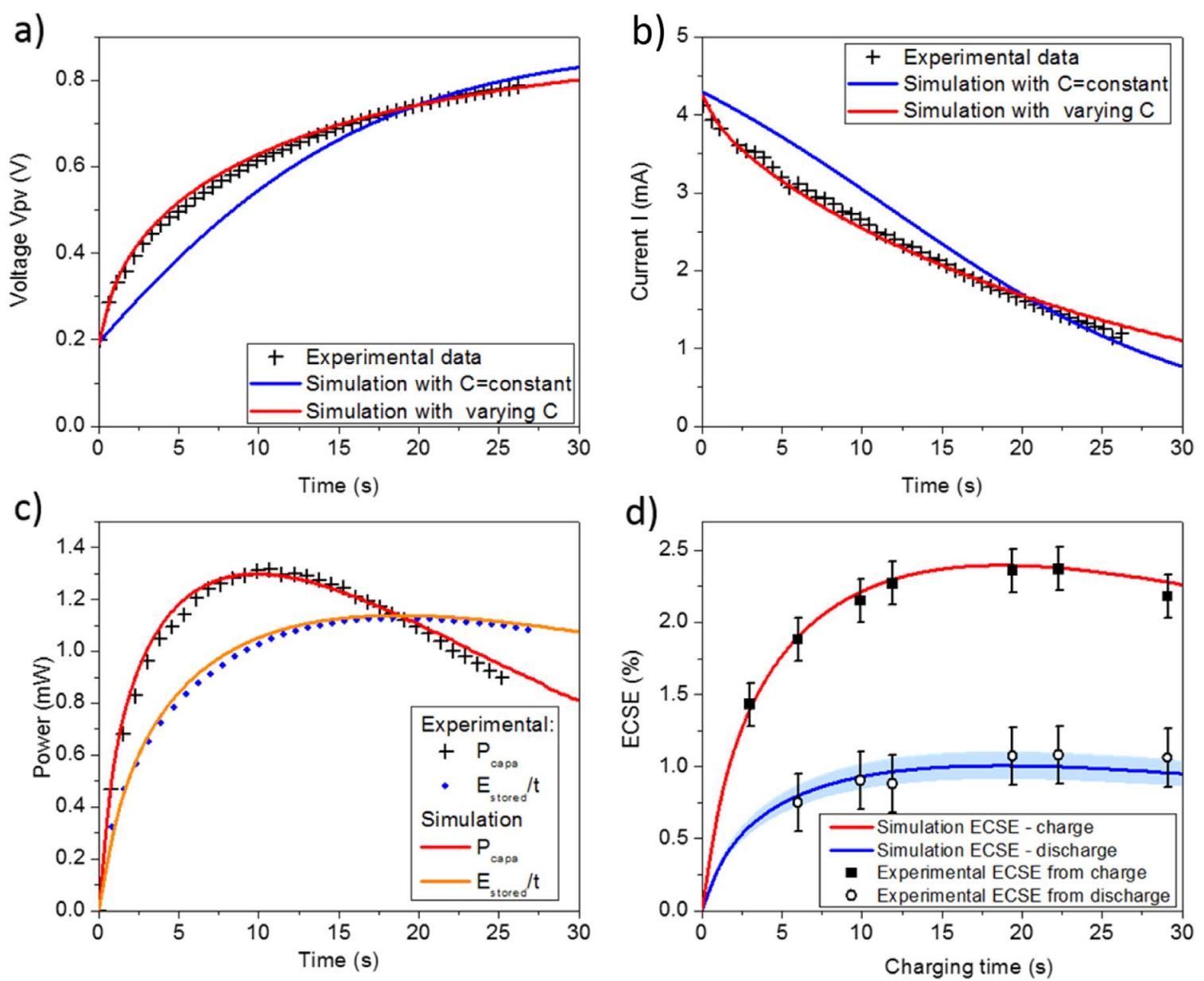

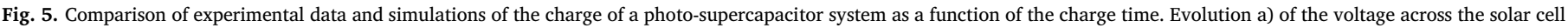

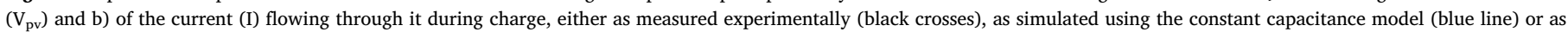

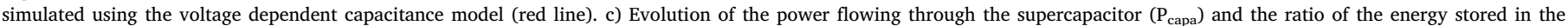

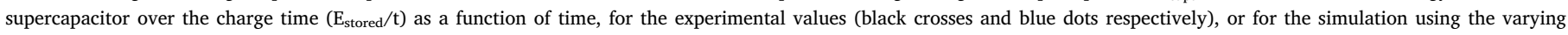

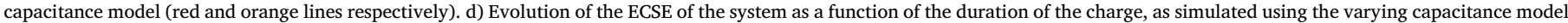

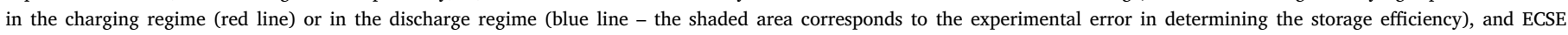

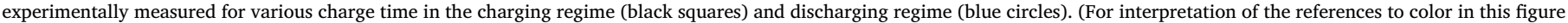
legend, the reader is referred to the web version of this article)

series and shunt resistances appears as a major pathway to achieving higher ECSE.

\subsection{Comparison between experiments and simulations}

\subsubsection{Experimental determination of ECSE}

Real-life applications of PSC require to know the amount of energy that can be extracted from the supercapacitor over a charge/discharge cycle, and the associated metric is the $\mathrm{ECSE}_{\max }$ measured from the discharge regime. However, the experimental determination of a PSC's discharge $\mathrm{ECSE}_{\max }$ requires to identify the time $t_{\mathrm{Emax}}$. The four previous studies $[10,11,14,15]$ that report the evolution of ECSE as a function of time in their systems usually do so by repeating the charge/discharge experiments for varying times of charge. While exact, this method can be long and may induce degradations of the system due to the electrical cycling of the supercapacitor and of the prolonged light exposure of the solar cell. These effects can thus penalize the accurate measurement of ECSE $_{\text {max }}$. An experimental method to determine the charging time for ECSE $_{\text {max }}$ with a minimal number of charge/discharge cycles would thus mitigate these effects. The ECSE is maximum when its time derivative is equal to 0 . It can be shown (See Appendix A) that this occurs for the time $t_{\text {Emax }}$ such as:
$P_{\text {capa }}\left(t_{\text {Emax }}\right)=\frac{1}{t_{\text {Emax }}} E_{\text {stored }}\left(t_{\text {Emax }}\right)$

where $P_{\text {capa }}(t)$ is the power flowing through the supercapacitor at time $t$. This expression demonstrates that, independently of any parameters and in particular of the capacitance, the ECSE is maximum when the power flowing through the capacitor is equal to the average of the power that flowed through it over time since the start of the charge. It is a condition that can be monitored experimentally during the charge regime through the measure of $\mathrm{P}_{\text {capa }}$. Usually, it is possible to measure simultaneously the voltage across the solar cell $\left(\mathrm{V}_{\mathrm{pv}}\right)$ and the current $\mathrm{I}$ it generates. From the onset of $V_{p v}$ and the value of $I$ at $t=0$ it is possible to determine the series resistance. The shunt resistance can be estimated from the saturation part of the charge curves. From these resistances, $V_{\text {capa }}$ and $i_{c}$ can be derived from the measure of $V_{p v}$ and $I$, and the power flowing into the supercapacitor can be calculated in real time. Integrating this power over the experimental time gives access to the stored energy, and it is possible to determine experimentally the moment $t_{\mathrm{Emax}}$ when the condition of Eq. (28) is satisfied. With this method, only two charge/discharge cycles are needed to measure EC$\mathrm{SE}_{\text {max }}$ : a first cycle which goes to the saturation of the voltage in order to determine $R_{s}$ and $R_{s h}$, and a second cycle (interrupted at $t_{E \max }$ ) where $\mathrm{ECSE}_{\text {max }}$ is measured from the discharge. The first measurement can be avoided if a preliminary characterization of the supercapacitor alone 
has allowed to extract $R_{s}$ and $R_{s h}$.

\subsubsection{Experiment and simulation comparison}

In order to demonstrate the validity of the model and of the method to identify ECSE $_{\max }$, simulations are compared to the results of chargedischarge experiments. A photo-supercapacitor system is realized by taking a $0.475 \mathrm{~cm}^{2}$ organic solar cell of PEDOT:PSS/PCDTBT: PC $_{71} \mathrm{BM} /$ PEIE/Aluminum (as reported in reference [9]) and a commercially available supercapacitor rated at $0.1 \mathrm{~F}$ (experimentally, it is found that the capacitance is $89+/-2 \mathrm{mF}$ ). The solar cell has a $\mathrm{V}_{\text {oc }}$ of $902 \mathrm{mV}$, a current density $\mathrm{J}_{\mathrm{sc}}$ of $9.85 \mathrm{~mA} / \mathrm{cm}^{2}$ corresponding to a current $\mathrm{I}_{\mathrm{sc}}=$ $4.68 \mathrm{~mA}$, a Fill Factor of $41.2 \%$ and an overall PCE of $3.60 \%$. These performances remain constant during the whole experiment. Chargedischarge experiments are performed under 1-sun illumination. At the end of the charge, the supercapacitor is disconnected from the solar cell and discharged in a load resistance of $35 \Omega$. The voltage across the solar cell and the current flowing through it are measured during the whole process, corresponding to the values $\mathrm{V}_{\mathrm{pv}}$ and $\mathrm{I}$ in the previous section. A first charging experiment is performed to determine the series and shunt resistances of the system. Values of $R_{s}=45+/-2 \Omega$ and $R_{s h}=$ $24 \mathrm{k} \Omega$ are found. Using the criteria established earlier, $R_{\mathrm{sh}}$ can be neglected as $R_{s h} \gg 10 \frac{V_{o c}}{I_{s c}}=1910 \Omega$. A simulation using these values for resistances, capacitance and solar cell parameters is performed (a comparison between the experimental I-V curve and its fit using the elliptical equation is presented in Supplemental Fig. S3). Fig. 5a shows the voltage across the solar cell and Fig. $5 \mathrm{~b}$ its current as a function of time during the charge regime. Simulations using the parameters and equations described earlier assuming a constant capacitance lead to a reasonable agreement for the initial and final state of the system but do not reproduce properly the experimental data during the charging process. This discrepancy can be explained by the fact that the equivalent electrical circuit used for the supercapacitor is too simplistic. Supercapacitors are known to have complex charge dynamics $[18,19]$ which need to be described by more sophisticated electrical equivalent circuits, such as circuits with more than one RC branch, or voltage dependent capacitance or time-dependent resistance. The presence of such effects in this experiment is confirmed by the fact that both the experimental apparent instantaneous capacitance (calculated as $C(t)=\frac{Q(t)}{V_{p v}(t)-R_{S} I(t)}$ with $Q(t)=\int_{0}^{t} I(\tau) d \tau$ and considering $\mathrm{R}_{\mathrm{s}}$ as constant), and the apparent series resistance (calculated as $R_{S}(t)=\frac{V_{p v}(t)-Q(t) / C}{I(t)}$ and considering that $\mathrm{C}$ is constant) vary with time (see Supplemental Fig. S4). Therefore, the model described in Section 2 needs to be modified. A straightforward approach consists in replacing either the series resistance or the capacitance with a simple function of the voltage. The best fits of voltage-dependent series resistance are obtained with exponential functions of $\mathrm{V}_{\text {capa }}$, leading to a diverging integral in Eq. (5) and can therefore not be used. So the model is adapted by replacing the value of $\mathrm{C}=89 \mathrm{mF}$ by a function of $\mathrm{V}_{\text {capa, }}$ such as:

$$
\begin{aligned}
& \text { If } V_{\text {capa }}<0.1 \mathrm{~V}: \quad C\left(V_{\text {capa }}\right)=0.025(\mathrm{~F}) \\
& \text { If } V_{\text {capa }}>0.1 \mathrm{~V}: C\left(V_{\text {capa }}\right)=\frac{1}{4.5} V_{\text {capa }}+0.00278(\mathrm{~F})
\end{aligned}
$$

This equation is determined numerically by fitting the curve of the apparent capacitance as a function of $\mathrm{V}_{\text {capa }}$. It has the advantage of remaining simple, and of verifying that the average of $\mathrm{C}\left(\mathrm{V}_{\text {capa }}\right)$ over the voltage range $0-0.8 \mathrm{~V}$ is equal to $0.093 \mathrm{~F}$, very close to the capacitance experimentally measured. Simulations performed with this function of $\mathrm{C}$ injected in the differential Eq. (5) (red lines in Figs. 5a and b) are in excellent agreement with the experimental voltage and current curves. As previously mentioned, with a variable capacitance Eq. (9) is no longer valid to determine the energy stored in the supercapacitor, and $\mathrm{E}_{\text {stored }}$ can only be calculated by integrating $\mathrm{P}_{\text {capa }}$ over time.

The simulation with adapted capacitance is then compared to the experimental data to demonstrate the accuracy of the criterion to determine the maximum ECSE. Fig. $5 \mathrm{c}$ plots the power flowing to the supercapacitor $P_{\text {capa }}(t)$ and the ratio $\frac{E_{\text {stored }}(t)}{t}$ as a function of time, both from the experimental data and from the simulation with varying capacitance. There is again a close agreement between the observations and the simulations. The two functions $\frac{E_{\text {stored }}(t)}{t}$ and $P_{\text {capa }}(t)$ become equal at $\mathrm{t}=19 \mathrm{~s}$. To verify that this time actually corresponds to $t_{\mathrm{Emax}}$, as suggested by Eq. (28), multiple charge-discharge experiments are repeated with varying charge times. The ECSE is calculated from both the charging and the discharging regime. For the charging regime, the energy stored is calculated as $E_{\text {stored }}=\int_{0}^{\text {end charge }} V_{\text {capa }}(t) I(t) d t$, using the experimental value of $R_{s}$ to calculate $V_{\text {capa }}$ from $V_{p v}$. The energy discharged from the supercapacitor is calculated as $E_{\text {stored }}=\int_{\text {start discharge }}^{\infty} V_{\text {capa }}(t) I(t) d t$. The values of ECSE measured from the charge and the discharge regimes for charging times equal to $3 \mathrm{~s}$, 6 s, 10 s, 12 s, 19 s, 22 s and 29 s are shown in Fig. 5d along with the simulation curves of ECSE as a function of time for the charge and the discharge regimes. The simulation of ECSE for the discharge regime is derived by using Eq. (11), with the experimental value of the energy storage efficiency, found to be $\eta_{\text {storage }}=42+/-4 \%$. There is a very close agreement between the simulations and the experimental values of ECSE for both the charging and the discharging regime. Experimentally, the maximum of ECSE happens between the points $\mathrm{t}=19 \mathrm{~s}$ $\left(\mathrm{ECSE}_{\text {charge }}=2.4+/-0.1 \%, \mathrm{ECSE}_{\text {Discharge }}=1.1+/-0.2 \%\right)$ and $\mathrm{t}=$ $22 \mathrm{~s}\left(\mathrm{ECSE}_{\text {charge }}=2.4+/-0.1 \%, \mathrm{ECSE}_{\text {Discharge }}=1.0+/-0.2 \%\right)$, which corresponds very well to the prediction from the method of Eq. (28). The ratio $\mathrm{ECSE}_{\max } / \mathrm{PCE}$ is equal to 0.65 . From the initial model of Fig. 4, a system with a FF of $41 \%$ should have a ratio $\mathrm{ECSE}_{\max } / \mathrm{PCE}$ equal to 0.74 in the ideal case and equal to 0.49 for $R_{s}=45 \Omega$. However, running the model with the variable capacitance described by Eq. (29) leads to very different ratios of $\mathrm{ECSE}_{\max } / \mathrm{PCE}$ as a function of the Fill Factor (See Supplemental Fig. S5). For a system with FF $=41 \%$, the new ratios $\mathrm{ECSE}_{\max } / \mathrm{PCE}$ are equal to 0.86 for an ideal circuit and 0.69 for a circuit with a Rs $=45 \Omega$, reasonably close to the experimental ratio of 0.65 . The difference corresponds to a variation in the measure of either PCE or ECSE of $0.2 \%$ (absolute), within the margins of error for both values. Overall, the experiments and the simulations are in very good agreement together once the voltage dependent capacitance and the parasitic resistances are taken into account. Here, the variable capacitance leads to an increase of the ratio of $\mathrm{ECSE}_{\max } / \mathrm{PCE}$ compared to the model scenario where $\mathrm{C}$ is constant. Therefore, controlling the variation of the capacitance with its voltage appears to be another major pathway to experimentally improve the ECSE of a photo-supercapacitor system.

\section{Conclusion}

In summary, a model of the operation of photo-supercapacitor systems has been proposed. This model is based on a simplified supercapacitor description including an ideal, constant capacitance, series and shunt resistance. The solar cell's electrical performance are described by a simple elliptical expression of its I-V characteristics, allowing to investigate easily the impact of its $V_{o c}, I_{s c}$ and Fill Factor. The time dependent non-linear differential equation of the system has been analytical solved in the ideal case (no series or shunt resistance) and numerically in the other cases, providing important insights on the operation of photo-supercapacitors. In the ideal case, the energy conversion and storage efficiency of the system is found to depend solely on the PCE and the Fill Factor of the solar cell, while the ratio $\frac{C V_{o c}}{I_{s c}}$ controls the time dynamics of ECSE and the optimal charge duration. For solar cells with excellent FF (and thus relatively good PCE) and negligible parasitic resistance, the theory predicts that the $\mathrm{ECSE}_{\max }$ should be in the range of $\sim 0.5$ PCE. For solar cells with poor FF (and thus poorer $\mathrm{PCE}$ ), the ratio $\mathrm{ECSE}_{\max } / \mathrm{PCE}$ is higher (up to 0.8 for a FF equal to 0.25 ). The impact of series and shunt resistances has also been investigated in details. It turns out that series resistances affect the dynamics of the 
charging regime but not the system's final state, whereas the shunt resistances modify the final state but have limited impact on the initial stage of the charge. Both resistances degrade the overall ECSE $_{\max }$ of the system. The exact decrease does not depend on the absolute value of these resistances, but rather on the way these resistances compare to $\frac{V_{o c}}{I_{s c}}$. More specifically, according to this model, parasitic resistances can be neglected if $R_{S} \ll V_{o c} / I_{s c}$ and $R_{s h} \frac{I_{s c}}{10} \geq V_{o c}$. In addition, if series resistances are high, too high a FF can reduce the $\mathrm{ECSE}_{\max }$ of the system. In other words, the capacitor parasitic resistances have to be optimized in accordance with the solar cell used in the photo-supercapacitor system.

An experimental method to determine ECSE $_{\max }$ both for the charge and the discharge regime has also been proposed. It requires a minimum number of 2 cycles of charge/discharge, and relies on the monitoring in real time of the power flowing to the supercapacitor and the ratio of the stored energy over the charge time. Both this method and the simulations were validated by comparison with experiments on a physical photo-supercapacitor system. These results suggest three pathways to improve the $\mathrm{ECSE}_{\max }$ of photo-supercapacitors. First and foremost, increasing the efficiency of the solar cell will directly impact the ECSE. Then, reducing the influence of the series and shunt resistance on the system will help drive the ECSE close to its ideal value. Third, the complex behavior of supercapacitors, whose effective capacitance may vary with voltage, allow to increase the ratio $\mathrm{ECSE}_{\max } / \mathrm{PCE}$ over its ideal theoretical value with constant capacitance. Overall, the methods and guidelines developed in this work should help the improvement of photo-supercapacitor systems.

\section{Acknowledgments}

This work has been partially supported by the National Science Foundation, grant NSF-1610899, and by the FRANCE BERKELEY FUND FBF \#2015-03. The authors would like to thank Dr. Abhinav Gaikwad and Martin Cowell for very helpful discussions and contributions.

\section{Appendix A. Derivations}

\section{A.1. Relating the fill factor $F$ and $V_{O}$}

By definition, the Fill Factor is defined such as:

$F=\frac{I_{p p \max } V_{\text {ppmax }}}{I_{s c} V_{o c}}$

where $I_{p p \max }$ and $V_{\text {ppmax }}$ are the current and the voltage of the solar cell at its maximum power point. They are defined such as:

$\left.\frac{d(I(V) V)}{d V}\right|_{V_{p p \max }}=0$

By using Eq. (1) of the manuscript, Eq. (A2) gives that:

$V_{\text {ppmax }}=V_{0}-\sqrt{V_{0}\left(V_{0}-V_{o c}\right)}$

From the expression of $V_{p p m a x}$, and the elliptical $\mathrm{I}(\mathrm{V})$ equation, $I_{p p \max }$ can be expressed and replaced in Eq. (A1), giving:

$F=\frac{V_{0}}{V_{o c}^{2}}\left(\sqrt{V_{0}}-\sqrt{V_{0}-V_{o c}}\right)^{2}$

Solving this equation leads to Eq. (2), the expression of $\mathrm{V}_{0}$ as a function of the Fill Factor $\mathrm{F}$.

\section{A.2. Calculation and approximation of $\delta V$}

$\delta \mathrm{V}$ is defined such as $V_{E \max }=V_{o c}-\delta V$. Eq. (22) and Eq. (1) lead to:

$\frac{\delta V}{V_{0}-V_{o c}+\delta V}=\frac{\left(V_{o c}-\delta V\right)}{2\left(V_{o c}-\delta V-\left(V_{0}-V_{o c}\right) \ln \left(\frac{\delta V}{V_{o c}}\right)\right)}$

Interestingly, according to Eq. (23), $\delta \mathrm{V}$ and thus $V_{E \max }$ are independent of either $I_{s c}$ and C. Neglecting the $\delta \mathrm{V}^{2}$ terms leads to the following simplification:

$\ln \left(\frac{\delta V}{V_{o c}}\right)=-\frac{V_{o c}}{2 \delta V}+\frac{V_{0}}{2\left(V_{0}-V_{o c}\right)}$

And by replacing $\mathrm{V}_{0}$ with its expression as a function of the Fill Factor $\mathrm{F}$ (Eq. (9)) gives:

$-2 \ln \left(\frac{\delta V}{V_{o c}}\right)=\frac{V_{o c}}{\delta V}-\frac{2 \sqrt{F^{3}}+F}{\left(2 \sqrt{F^{3}}-3 F+1\right)}$

The exact solution of this equation is:

$\delta V=V_{o c} \exp \left[\frac{1}{2} \frac{2 \sqrt{F^{3}}+F}{\left(2 \sqrt{F^{3}}-3 F+1\right)}+W\left[-\frac{1}{2} \exp \left(\frac{1}{2} \frac{2 \sqrt{F^{3}}+F}{\left(2 \sqrt{F^{3}}-3 F+1\right)}\right)\right]\right]=V_{o c} \exp [g(F)]$

where $W$ is the lambert function. The function $\mathrm{g}(\mathrm{F})$ is defined as shown here by Eq. (A8) and groups together all the terms dependent on $\mathrm{F}$ within the exponential term. We are looking for an approximation of the form:

$\delta V \approx V_{o c} \exp [-a F+b]$

According to Eq. (18), the parameters $a$ and $b$ should satisfy: 
$a F-b=\frac{e^{a F-b}}{2}-\frac{1}{2} \frac{2 \sqrt{F^{3}}+F}{\left(2 \sqrt{F^{3}}-3 F+1\right)}=\widetilde{f}(a, b, F)$

Using the Taylor formula around $F=0.25$ (the lowest value $\mathrm{F}$ can take in the model), $a$ and $b$ can be approximated as

$a \frac{F}{4}-b=\tilde{f}\left(a, b, F=\frac{1}{4}\right)$

$a=-\frac{\partial \widetilde{f}}{\partial F}\left(a, b, F=\frac{1}{4}\right)$

We found $a \sim 5,3$ and $b \sim 0.07$.

A.3. Derivation of $t_{E \max }$ and $E C S E_{\max }$ from $V_{E \max }$ in part 4.1 .2

The voltage at ECSE max is equal to $V_{E \max }=V_{o c}\left(1-e^{g(F)}\right)$. Moreover, Eq. (17) states that:

$t(V)=\frac{C V_{o c}}{I_{s c} V_{0}}\left(V-\left(V_{0}-V_{o c}\right) \ln \left[1-\frac{V}{V_{o c}}\right]\right)$

Therefore:

$t_{E \max }=\frac{C V_{o c}}{I_{s c} V_{0}}\left(V_{o c}\left(1-e^{g(F)}\right)-\left(V_{0}-V_{o c}\right) g(\mathrm{~F})\right)$

By using the expression of $V_{O}$ as a function of $V_{o c}$ and $\mathrm{f}(\mathrm{F})$ :

$t_{E \max }=\frac{C}{I_{s c} f(F)}\left(V_{o c}\left(1-e^{g(F)}\right)-V_{o c}(f(F)-1) g(F)\right)$

$t_{E \max }=\frac{C V_{o c}}{I_{s c}} \frac{\left(\left(1-e^{g(F)}\right)+(1-f(F)) g(F)\right)}{f(F)}=\frac{C V_{o c}}{I_{s c}} h(F)$

where:

$h(F)=\frac{\left(\left(1-e^{g(F)}\right)+(1-f(F)) g(\mathrm{~F})\right)}{f(F)}$

$h(F)=\frac{(4 F-1)\left(1-e^{g(F)}\right)+\left(3 F-2 \sqrt{F^{3}}-1\right) g(F)}{2 \sqrt{F^{3}}+F}$

With:

$g(F)=\frac{1}{2} \frac{2 \sqrt{F^{3}}+F}{\left(2 \sqrt{F^{3}}-3 F+1\right)}+W\left[-\frac{1}{2} \exp \left(\frac{1}{2} \frac{2 \sqrt{F^{3}}+F}{\left(2 \sqrt{F^{3}}-3 F+1\right)}\right)\right]$

So:

$h(F)=\frac{(4 F-1)\left(1-e^{g(F)}\right)}{2 \sqrt{F^{3}}+F}+\frac{\left(3 F-2 \sqrt{F^{3}}-1\right) W\left[-\frac{1}{2} \exp \left(\frac{1}{2} \frac{2 \sqrt{F^{3}}+F}{\left(2 \sqrt{F^{3}}-3 F+1\right)}\right)\right]}{2 \sqrt{F^{3}}+F}-\frac{1}{2}$

From $\operatorname{ECSE}(t)=\frac{1 / 2 C V(t)^{2}}{P_{\text {light }} t}$ and the known values of $t_{\text {Emax }}$ and $V_{E \max }$ it is possible to calculate $\mathrm{ECSE}_{\max }$ :

$E C S E_{\text {max }}=\frac{\frac{1}{2} C V_{o c}^{2}\left(1-e^{g(F)}\right)^{2}}{P_{\text {light }} \frac{C V_{\text {oc }}}{I_{\text {sc }}} h(F)}$

$E C S E_{\max }=\frac{I_{s c} V_{o c}\left(1-e^{g(F)}\right)^{2}}{2 P_{\text {light }} h(F)}$

$E C S E_{\text {max }}=\frac{I_{s c} V_{o c} F}{P_{\text {light }}} \frac{\left(1-e^{g(F)}\right)^{2}}{2 F h(F)}$

$E C S E_{\max }=P C E \frac{\left(1-e^{g(F)}\right)^{2}}{2 F h(F)}=\operatorname{PCEk}(F)$

where:

$k(F)=\frac{\left(1-e^{g(F)}\right)^{2}}{2 F h(F)}=\frac{\left(2 \sqrt{F^{3}}+F\right)\left(1-e^{g(F)}\right)^{2}}{2 F\left((4 F-1)\left(1-e^{g(F)}\right)+\left(3 F-2 \sqrt{F^{3}}-1\right) g(F)\right)}$

And $g(F)$ is defined with Eq. (A.19). A numerical plot of $k(F)$ is shown in Supplemental Fig. S3. 


\section{A.4. Equations to calculate the circuit state for each value of $V_{p v}$ in the simulation}

For each time $\mathrm{t}\left(\mathrm{V}_{\mathrm{pv}}\right)$, from the value of $V_{p v}$, it is straightforward to determine $\mathrm{I}\left(\mathrm{V}_{\mathrm{pv}}\right)$ from the parametric equations:

$V_{\text {capa }}(t)=V_{p v}(t)-R_{S} I\left(V_{p v}(t)\right)$

$Q(t)=C\left(V_{\text {capa }}(t)\right) V_{\text {capa }}(t)$

$i_{c}(t)=\frac{V_{\text {capa }}(t)}{R_{\text {sh }}}$

$P_{\text {capa }}(t)=V_{\text {capa }}(t) i_{c}(t)$

Once these values have been calculated for every time $t$, it is verified that for each value of $t$ :

$Q(t)=\int_{0}^{t} i_{c}(\tau) d \tau$

And the energy stored is calculated as:

$E_{\text {stored }}(t)=\int_{0}^{t} P_{\text {capa }}(\tau) d \tau$

\section{A.5. Derivation of ECSE with regard to time}

$\operatorname{ECSE}(t)=\frac{E_{\text {stored }}(t)}{E_{\text {light }}(t)}=\frac{\int_{0}^{t} V_{\text {capa }}(\tau) * i_{c}(\tau) d \tau}{P_{\text {light }}{ }^{*} t}$

$\frac{d E C S E(t)}{d t}=\frac{V_{\text {capa }}(t)^{*} i_{c}(t)^{*} P_{\text {light }}{ }^{*} t-\int_{0}^{t} V_{\text {capa }}(\tau)^{*} i_{c}(\tau) d \tau^{*} P_{\text {light }}}{\left(P_{\text {light }}{ }^{*} t\right)^{2}}$

$\frac{d \operatorname{ECSE}(t)}{d t}=0 \rightarrow V_{\text {capa }}(t)^{*} i_{c}(t)^{*} t-\int_{0}^{t} V_{\text {capa }}(\tau)^{*} i_{c}(\tau) d \tau=0$

$V_{\text {capa }}\left(t_{\text {max }}\right) * i_{c}\left(t_{\text {max }}\right)=\frac{1}{t_{\max }} * \int_{0}^{t} V_{\text {capa }}(\tau)^{*} i_{c}(\tau) d \tau=\frac{1}{t_{\max }} * E_{\text {stored }}\left(t_{\text {max }}\right)$

Which gives:

$P_{\text {capa }}\left(t_{E \max }\right)=\frac{1}{t_{\text {Emax }}} E_{\text {stored }}\left(t_{E \max }\right)$

\section{Appendix B. Supplementary material}

Supplementary data associated with this article can be found in the online version at http://dx.doi.org/10.1016/j.solmat.2017.07.034.

\section{References}

[1] C.-T. Chien, P. Hiralal, D.-Y. Wang, I.-S. Huang, C.-C. Chen, C.-W. Chen, G.A.J. Amaratunga, Graphene-based integrated photovoltaic energy harvesting/storage device, Small 11 (2015) 2929-2937.

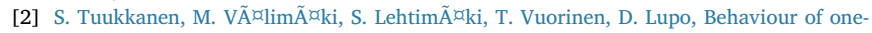
step spray-coated carbon nanotube supercapacitor in ambient light harvester circuit with printed organic solar cell and electrochromic display, Sci. Rep. 6 (2016) 22967.

[3] A.E. Ostfeld, A.M. Gaikwad, Y. Khan, A.C. Arias, High-performance flexible energy storage and harvesting system for wearable electronics, Sci. Rep. 6 (2016) 26122.

[4] Z. Ouyang, S.N. Lou, D. Lau, J. Chen, S. Lim, P. Hsiao, D. Wang, R. Amal, Y.H. Ng, A. Lennon, Monolithic integration of anodic molybdenum oxide pseudocapacitive electrodes on screen-printed silicon solar cells for hybrid energy harvesting-storage systems, Adv. Energy Mater. (2016), http://dx.doi.org/10.1002/aenm.201602325.

[5] A.P. Cohn, W.R. Erwin, K. Share, L. Oakes, A.S. Westover, R.E. Carter, R. Bardhan, C.L. Pint, All silicon electrode photocapacitor for integrated energy storage and conversion, Nano Lett. 15 (2015) 2727-2731, http://dx.doi.org/10.1021/acs.nanolett.5b00563.

[6] D. Schmidt, M.D. Hager, U.S. Schubert, Photo-rechargeable electric energy storage systems, Adv. Energy Mater. (2015) (n/a-n/a).

[7] G. Wee, T. Salim, Y.M. Lam, S.G. Mhaisalkar, M. Srinivasan, Printable photo-supercapacitor using single-walled carbon nanotubes, Energy Environ. Sci. 4 (2011) 413-416, http://dx.doi.org/10.1039/C0EE00296H.

[8] Z. Yang, L. Li, Y. Luo, R. He, L. Qiu, H. Lin, H. Peng, An integrated device for both photoelectric conversion and energy storage based on free-standing and aligned carbon nanotube film, J. Mater. Chem. A. 1 (2013) 954-958.

[9] B.P. Lechêne, M. Cowell, A. Pierre, J.W. Evans, P.K. Wright, A.C. Arias, Organic solar cells and fully printed super-capacitors optimized for indoor light energy harvesting, Nano Energy 26 (2016) 631-640.

[10] Y. Fu, H. Wu, S. Ye, X. Cai, X. Yu, S. Hou, H. Kafafy, D. Zou, Integrated power fiber for energy conversion and storage, Energy Environ. Sci. 6 (2013) 805-812, http://dx.doi. org /10.1039/C3EE23970E.

[11] J. Xu, H. Wu, L. Lu, S.-F. Leung, D. Chen, X. Chen, Z. Fan, G. Shen, D. Li, Integrated photosupercapacitor based on Bi-polar TiO2 nanotube arrays with selective one-side plasmaassisted hydrogenation, Adv. Funct. Mater. 24 (2014) 1840-1846.

[12] M. Skunik-Nuckowska, K. Grzejszczyk, P.J. Kulesza, L. Yang, N. Vlachopoulos, L. Hagman, E. Johansson, A. Hagfeldt, Integration of solid-state dye-sensitized solar cell with metal oxide charge storage material into photoelectrochemical capacitor, J. Power Sources 234 (2013) 91-99, http://dx.doi.org/10.1016/j.jpowsour.2013.01.101.

[13] X. Zhang, X. Huang, C. Li, H. Jiang, Dye-sensitized solar cell with energy storage function through PVDF/ZnO nanocomposite counter electrode, Adv. Mater. 25 (2013) 4093-4096.

[14] X. Chen, H. Sun, Z. Yang, G. Guan, Z. Zhang, L. Qiu, H. Peng, A novel "energy fiber" by coaxially integrating dye-sensitized solar cell and electrochemical capacitor, J. Mater. Chem. A 2 (2014) 1897-1902, http://dx.doi.org/10.1039/C3TA13712K.

[15] Z. Zhang, X. Chen, P. Chen, G. Guan, L. Qiu, H. Lin, Z. Yang, W. Bai, Y. Luo, H. Peng Integrated polymer solar cell and electrochemical supercapacitor in a flexible and stable fiber format, Adv. Mater. 26 (2014) 466-470.

[16] N. Bagheri, A. Aghaei, M.Y. Ghotbi, E. Marzbanrad, N. Vlachopoulos, L. Haggman, M. Wang, G. Boschloo, A. Hagfeldt, M. Skunik-Nuckowska, P.J. Kulesza, Combination of asymmetric supercapacitor utilizing activated carbon and nickel oxide with cobalt polypyridyl-based dye-sensitized solar cell, Electrochim. Acta 143 (2014) 390-397, http://dx.doi.org/10.1016/j.electacta.2014.07.125.

[17] T. Chen, L. Qiu, Z. Yang, Z. Cai, J. Ren, H. Li, H. Lin, X. Sun, H. Peng, An integrated energy wire for both photoelectric conversion and energy storage, Angew. Chem. Int. Ed. 51 (2012) 11977-11980.

[18] V. Sedlakova, J. Sikula, J. Majzner, P. Sedlak, T. Kuparowitz, B. Buergler, P. Vasina, Supercapacitor equivalent electrical circuit model based on charges redistribution by diffusion, J. Power Sources 286 (2015) 58-65.

[19] L. Zubieta, R. Bonert, Characterization of double-layer capacitors for power electronics applications, IEEE Trans. Ind. Appl. 36 (Jan), pp. 199-205. 